KALAM, p-ISSN: 0853-9510 e-ISSN: 2540-7759

http://ejournal.radenintan.ac.id/index.php/KALAM

Volume 10, No. 2, Desember 2016, halaman 295 - 312

\title{
Harmoni Sosial Dalam Keberagaman Dan Keberagamaan Masyarakat Minoritas Muslim Papua Barat
}

\author{
Ismail Suardi Wekke \\ STAIN Sorong, Papua \\ iswekke@gmail.com
}

\begin{abstract}
Abstrak
Papua Barat menjadi wilayah dimana keberagamaan dan keberagaman mengalami perjumpaan dengan etnisitas. Untuk itu, diperlukan sebuah eksplorasi untuk mengidentifikasi tentang keberadaan agama sebagai aspek yang mempersatukan. Dengan demikian, artikel ini bertujuan untuk menganalisis perbedaan agama yang menjadi pilihan pribadi masyarakat Papua Barat. Pada saat yang sama, justru agama juga menjadi perekat kehidupan masyarakat. Penelitian ini dilaksanakan di Sorong Raya, Papua Barat. Wawancara mendalam dan pengamatan tidak berpartisipasi digunakan untuk mengumpulkan data. Untuk. kepentingan triangulasi data dilakukan diskusi terarah, termasuk. penyajian hasil penelitian awal melalui forum diskusi sebanyak dua kali. Artikel ini mendiskusikan perjumpaan agama-agama melabirkan harmoni dan kebersamaan. Keberadaan agama justru menjadi bagian yang tidak menjadi pembeda. Babkan dalam beberapa hal, kegiatan keagamaan dijadikan sebagai kegiatan bersama walaupun berbeda-beda agama. Akbirnya, artikel ini mendiskusikan beberapa hal berkaitan dengan budaya yang juga tetap memberikan ruang bagi perbedaanperbedaan dalam memilih keyakinan masing-masing.
\end{abstract}

\section{Abstract}

West Papua is region where diversity and religiosity encounter with ethnicity. Therefore, it is a need to explore to identify on religion existence as an aspect to unite. In addition, this article will analyses religious variety which private choose of West Papua community. In the same time, 
religion is a adhesive of community life. This research was conducted in great area of Sorong, West Papua. In-depth interview and nonparticipant observation were employed to collect data. Triangulation technique was conducted through focus group discussion twice. This article discusses religions encounters in order to strengthen harmony and togetherness. Agama existence is a part of unity which not a difference. Moreover, in some cases, religious activities are activity together even thought they choose different religion. Finally, this article discusses some subjects in line with culture to provide space for difference in choosing each faith.

Keywords: kebersamaan, keberagaman, keberagamaan, etnisitas

\section{A. Pendahuluan}

Papua senantiasa dilabeli dengan konflik, kekerasan, dan keterbelakangan. Banyak pula stigma yang menjadikan Papua seperti lambang dari pemberontakan. Seolah-olah kehidupan di Papua sangatlah tidak bersahabat dan menjadi ladang penindasan. Padahal, di tengah citra buruk itu justru Papua adalah tempat yang sangat damai dan harmonis. Penyelenggaraan ritual keagamaan tidak pernah mendapatkan halangan. Kesulitan untuk mendirikan rumah ibadah tidak pernah terjadi. Sementara ekspresi keberagamaan juga selalu tidak pernah menemui hambatan. Semua ini luput dari perhatian. Padahal jikalau saja mengenal orang Papua dengan lebih dekat, maka akan didapatkan kehangatan sebuah persaudaraan yang tanpa pamrih dan apa adanya. Mereka memperlakukan orang lain sebagai keluarga sehingga menjaga harkat, martabat dan kehormatan diri sendiri sama dengan yang dilakukannya untuk orang lain.

Papua seolah selalu identitik kekerasan, tambang emas. Padahal, melampaui itu semua, masyarakat Papua adalah masyarakat yang harmonis. Persaudaraan menjadi pilar utama kehidupan masyarakat. Mereka sejak awal sudah menjadikan kehidupan sebagai bagian keadaban untuk saling terkait dan mendukung. Bukan hanya sesama agama. Bahkan dalam urusan politik dan agama yang menjadi pemicu konflik, mereka tetap saja dapat guyub. Ini dapat dilihat di rumah orang tua, mereka terbiasa menyediakan ruang tamu dengan ukuran lebih besar dibandingkan rumah sang anak. Ini dilakukan demi menjadi ruang bagi keluarga 
besar untuk berkumpul dalam setiap perayaan keagamaan salah satu anggota keluarga. Rumah orang tua menjadi tempat berkumpul anak dan cucu walaupun mereka sesungguhnya memilih agama yang berbeda-beda.

Proses transformasi atau konversi agama tidak menjadi isu konfliktual. Oleh karena dipandang bahwa urusan agama adalah pilihan masing-masing individu dan tidak terkait dengan pihak lain. Seseorang yang beragama justru akan memperkuat ikatan sosial dengan masyarakat dan tidak akan mengisolasi diri, serta merusak hubungan dengan keluarga yang dimiliki. Suku Kokoda dan Arandai, dua di antara masyarakat Papua yang sudah sejak awal memeluk Islam, hidup berdampingan dengan kelurga dalam suku besar dengan bersama-sama mendiami wilayah adat yang mereka miliki tanpa pernah berselisih apapun. Termasuk dalam urusan pembagian hak ulayat tanah. Sementara Suku Dani di Lembah Baliem, Wamena yang sejak 1980 sudah mulai memeluk agama Islam. Begitu juga dengan Suku Abun di Sausafor, Kabupaten Tambrauw, mereka beralih untuk memeluk agama Islam setelah sebelumnya hanya menganut faham animisme.

Agama sejatinya adalah berdasarkan praktik lingkungan dan dijadikan sebagai bagian dari lingkungan sosial ${ }^{1}$. Dengan demikian, lingkungan sosial jugalah yang menentukan bagaimana agama itu menjadi instrumen yang menggerakkan masyarakat. Sementara di Tibet, agama menjadi alat untuk menjaga kelangsungan lingkungan. Kesadaran ini diturunkan oleh generasi sebelumnya dengan menekankan kepada sikap etik keagamaan terhadap penjagaan lingkungan ${ }^{2}$. Begitu juga di Nepal, lingkungan dapat terjaga dan dijadikan sebagai sandaran hidup bagi masyarakat karena adanya faktor agama yang senantiasa mendukung kampanye pelestarian lingkungan ${ }^{3}$. Dengan dukungan politik, maka secara bersama-sama,

${ }^{1}$ E. Durkheim, "The Elementary Forms of Religious Life" dalam M. Lambek (ed.), A Reader in the Anthropology of Religion, (Malden: Blackwell Publishing, 2002), h. 34-49.

${ }^{2}$ C. Ramble, The Navel of the Demoness: Tibetan Buddhism and Civil Religion in Highlight Nepal, (Oxford: Oxford University Press, 2008).

3 S. Stevens, "Annapurna Conservation Area: Empowerment, Conservation and Development in Nepal" dalam Stevens, S. (ed.), Conservation Through Cultural Survival (Washington D.C.: Island Press, 1997), h. 237-261. 
agama juga dapat dijadikan sebagai alat untuk melanggengkan legitimasi ${ }^{4}$. Praktik di Papua Nugini menunjukkan bahwa dengan kombinasi antara agama dan politik kemudian menjadi kesatuan untuk memberikan arahan dan penekanan terhadap agenda pemerintahan. Dalam lingkungan yang terbatas, agama dapat pula menjadi bagian untuk menjadi pertimbangan utama dalam pengelolaan kelas pembelajaran bahasa ${ }^{5}$.

Kajian ini menjadi bagian yang melengkapi mozaik studi Islam di Papua Barat yang mencakup arsitektur ${ }^{6}$, entitas dakwah dan budaya Islam 7 , ekspresi keberagamaan ${ }^{8}$, pendidikan Islam ${ }^{9}$, kurikulum $^{10}$, pendidikan dan pemberdayaan ${ }^{11}$, dan juga tentang pernikahan etnis Bugis ${ }^{12}$. Kesemuanya menjadikan sajian ini dapat

${ }^{4}$ P. West, Conservation is Our Government Now: The Politics of Ecology in Papua New Guinea, (Durham: Duke University Press, 2006).

5 I. S. Wekke \& M. A. Lubis, "A Multicultural Approach in Arabic Language Teaching: Creating Equality at Indonesian Pesantren Classroom Life" dalam Sosiobumanika, Jurnal Pendidikan Sains Sosial dan Kemanusiaan, Volume 1, Nomor 2, (2008), h. 295-310.

6 I. S. Wekke, "Masjid di Papua Barat: Tinjauan Ekspresi Keberagamaan Minoritas Muslim dalam Arsitektur" dalam El Harakah, Jurnal Budaya Islam, Volume 15, Nomor 2, (2013), h. 124-129.

7 I. S. Wekke dan Y. R. Sari, "Tifa Syawat dan Entitas Dakwah dalam Budaya Islam: Studi Suku Kokoda Sorong Papua Barat" dalam Thaqafiyyat, Jurnal Kajian Budaya Islam, Volume 13, Nomor 1, (2012), h. 163-186.

8 I. S. Wekke, E. Gunaisah, Suyatno, "Identitas dan Ekspresi Keberagamaan Nelayan Muslim: Masyarakat Pesisir Raja Ampat Papua Barat”, Prosiding dalam Seminar Nasional Kelautan dan Perikanan, Politeknik Kelautan dan Perikanan Sorong, 10 Maret 2015.

9 I. S. Wekke, "Pendidikan Islam dan Pemberdayaan Masyarakat: Tinjauan Pendidikan Vokasional Pesantren Roudhatul Khuffadz, Sorong" dalam Hermenia, Jurnal Kajian Islam Interdisipliner, Volume 10, Nomor 1, (2011), h. $25-53$.

10 I. S. Wekke, "Pesantren dan Pengembangan Kurikulum Kewirausahaan: Kajian Pesantren Roudhatul Khuffadz Sorong Papua Barat" dalam Jurnal Inferensi, Volume 6, No. 2 (2012), h. 203-226.

11 I. S. Wekke, "Religious Education and Empowerment: Study on Pesantren in Muslim Minority West Papua" dalam Miqot, Jurnal Ilmu-ilmu Keislaman, Volume 37, No. 2, (2013), h. 374-395.

12 I. S. Wekke, "Islam dan Adat dalam Pernikahan Masyarakat Bugis di Papua Barat" dalam Thaqafiyyat, Jurnal Kajian Budaya Islam, Volume 13, Nomor 2, (2012). 
menjadi bagian dalam pemahaman tentang minoritas muslim. Kajian ini diharapkan dapat memberikan pemahaman yang lebih lengkap dan jernih tentang situasi keragaman dan keberagamaan di Papua Barat, di tengah referensi dan konstruksi pengetahuan yang lebih memotret kekerasan rasial dan keagamaan di Papua yang justru kian mengeskalasi konflik.

\section{B. Persaudaraan dan Ikatan Emosional sebagai Perekat}

Spirit persaudaraan dalam konteks keluarga di Fak-Fak Papua Barat disebut dengan semboyan "Satu Tungku Tiga Batu". Ketika sebuah tungku digunakan untuk memasak, paling tidak memerlukan tiga batu. Lambang tiga batu itulah yang menjadi metafora keragaman keyakinan. Sehingga bagi sebuah keluarga, tidak ada masalah perbedaan agama, sekalipun tiga agama (Islam, Protestan, dan Katolik). Agama justru dijadikan alat untuk lebih bersatu dan guyub bersama-sama menopang keberlangsungan masyarakat. Perayaan agama menjadi sarana saling mengunjungi, menyapa, bertemu, dan berbagi. 'Merayakan bersama' sebuah momentum keagamaan untuk dijadikan waktu membantu keluarga yang lain. Perayaan Idul Fithri menjadi kesempatan bagi masyarakat Protestan dan Katolik membantu saudara muslimnya memasak sebagai persiapan menyambut hari raya. Sementara bagi warga muslim, ketika Natal juga menjadi kesempatan bagi mereka turut membantu memasak dan mempersiapkan hidangan dalam menyambut tamu atau perayaan misa sepanjang Desember.

Sementara di Kepulauan Raja Ampat dikenal semboyan "Satu Rumah Empat Pintu". Di samping Islam, Katolik, dan Protestan, animisme juga diberikan penghormatan yang sama sebagai bagian dari keluarga. Mereka memiliki keragaman agama antara satu dengan yang lainnya dalam sebuah rumah, bahkan sampai empat agama yang berbeda. Hal ini menunjukkan bahwa mereka menempatkan toleransi sebagai pilar kehidupan. Jikalau ada pilihan agama yang berbeda antar penghuni rumah, maka tidak dijadikan ruang memutuskan ikatan kekeluargaan. Ungkapan "sa pu keluarga" yang berarti saya punya keluarga menjadi dasar ikatan sosial dalam masyarakat. Agama apapun yang dianut, yang dapat berbeda dan mengalami pengubahan kapan saja, bukanlah 
penyebab runtuhnya persaudaraan yang sudah terbangun sejak awal.

Menjelang MTQ tingkat Provinsi Papua Barat 2014, Imam Masjid Al-Bitrul, Kiyai H. Saleh Jauhar mengalami pemukulan dari pemuda mabuk ketika akan mengisi jadwal siaran di RRI Kota Sorong. Saat itu masih gelap karena siaran dilaksanakan di waktu shubuh. Kiyai Saleh tidak dapat mengenali pelaku. Justru keluarga oknum yang beragama Protestan itulah yang menyerahkan pelaku langsung ke kantor polisi. Sementara pemuda Gereja di Pasar Baru menjaga masjid al-Jihad sebagai bentuk kehati-hatian karena merebaknya isu akan adanya saling serang antar dua kelompok berbeda agama. Sementara remaja masjid menjaga gereja Pantekosta yang berada di Sorong Pusat. Hanya hitungan menit setelah muncul isu itu, ketua Majelis Ulama Indonesia Kota Sorong dan beberapa pastor dan pendeta sudah bertemu. Kemudian mereka bersama-sama berkeliling ke beberapa masjid dan gereja untuk menyampaikan kejadian sebenarnya. Kurun waktu dua jam, isu yang beredar dapat diredam dan tidak terjadi pertengkaran apapun yang tidak diinginkan. Akhirnya, MTQ berjalan dengan sukses dan tanpa menemui kendala apapun. Oleh karena Kota Sorong merupakan tempat transit bagi seluruh kafilah Musabaqah Tilawatil Qur'an (MTQ) yang menuju Raja Ampat dengan menggunakan kapal feri. Jikalau saja terjadi masalah di Kota Sorong, maka pelaksanaan MTQ dapat saja gagal.

Sama halnya dengan perayaaan Natal, saat itu semua penduduk Aimas, Kabupate Sorong, berusaha memeriahkan jamuan makan yang dilaksanakan Stepanus Malak, tokoh masyarakat. Sementara di Malanu, Kota Sorong, Lamberthus Jitmau juga melaksanakan syukuran Natal dengan menjamu masyarakat. Di kedua tempat tersebut, masing-masing dimeriahkan dengan penduduk muslim untuk memberikan selamat Natal kepada empunya acara. Tidak ada kekahawatiran akan soal makanan yang tidak sesuai dengan kaidah Islam karena tukang masak yang mempersiapkan hidangan justru berasal dari kalangan muslim. Demikian pula alat-alat makan yang digunakan sepanjang acara semuanya berasal dari perusahaan catering yang dijalankan muslim. Sebelum dan setelah Natal, tetangga muslim senantiasa membantu persiapan acara dan bahkan membersihkan tempat acara sesuai 
perhelatan. Mereka juga mengirimkan bingkisan kepada tetangga yang merayakan Natal. Sebagaimana ketika umat Islam merayakan Idul Fithri dan Idul Adha, senantiasa mendapatkan kiriman bingkisan pula dari tetangga Protestan dan Katolik.

Keberlangsungan persaudaraan di atas bukan hanya momentual saja. Setiap hari anak-anak bergaul tanpa mempersalahkan persoalan identitas agama. Warga lintas iman juga saling berkunjung satu sama lain. Selain itu, perayaan hari keagamaan merupakan bagian yang menjadi keharusan dirayakan bersama, siapapun yang berada di Papua dan Papua Barat. Seperti perayaan Injil masuk di Tanah Papua setiap tahun pada tanggal 5 Februari. Perayaan ini tidak saja secara khusus untuk umat Protestan. Bagi kalangan muslim, perayaan ini juga patut dirayakan. Keberadaan dan perkembangan Protestan tidak dapat dilepaskan dari Kerajaan Ternate dan Kerajan Tidore yang menjadikan Islam sebagai agama resmi kerajaan. Justru awal mula penyebaran Protestan di Pulau Mansinam, yang menjadi bagian Kabupaten Manokwari saat ini, justru ditunjukkan oleh Sultan Ternate dan pesatnya perkembangan Protestan didukung sepenuhnya oleh Sultan Tidore dengan memberikan kesempatan kepada para misionaris untuk menyebarkan ke kawasan yang belum memeluk agama apapun.

Secara berkala kelompok-kelompok rebana atau kasidah di Kota Sorong mengadakan lomba sebagai ajang silaturahmi. Proses latihan dan penyiapan kostum tidak saja didukung oleh pengurus masjid, tetapi juga beberapa penduduk sekitar masjid yang berbeda agama juga turut menyumbang. Bahkan di Masjid At-Taubah, Malanu Kota Sorong, salah satu warga sekitar menyumbang dengan angka sampai puluhan juta rupiah, karena lomba tersebut tidak hanya membawa identitas masjid. Warga wilayah perumahan dengan ringan tangan turut menyumbang disertai keinginan menjadikan ajang lomba sebagai perkenalan sesama warga.

\section{Agama dan Keberagamaan di Papua Barat}

Islam bersama-sama dengan Protestan dan Katolik menjadi pilar keberagamaan masyarakat Papua Barat. Di beberapa lokasi, terdapat pula masyarakat Hindu dan Budha. Di Aimas, Kabupaten Sorong beberapa pegawai Kementerian Agama diangkat untuk 
mengurus bimbingan masyarakat. Sementara di Kota Sorong, ada pagoda sangat representatif yang menjadi tempat ibadah masyarakat Budha. Begitu juga masjid dan gereja, memiliki fasilitas yang relatif memadai. Sebuah kubah masjid di Aimas saja menghabiskan sampai seratus juta rupiah. Melalui dukungan anggaran daerah, beberapa masjid memiliki mobil ambulan untuk dijadikan sebagai sarana pelayanan bagi jamaah masjid.

Tipikal pengurus masjid di Kota Sorong justru leluasa membangun sekolah dan madrasah. Terdapat sekolah atau lembaga pendidikan yang unggul di dalam Masjid Al-Akbar dan Masjid AlJihad. Ketika mendaftar di SD Al-Jihad, sejak dini hari pukul 03.00, orang tua calon murid rela antri agar memiliki peluang untuk mendapatkan formulir pendaftaran. Adapun di dalam Masjid AlAkbar yang menjadi masjid agung terdapat pengelolaan gedung pertemuan dan poliklinik. Di Masjid ini pulalah tempat bagi Majelis Ulama Indonesia dan organisasi muslim lainnya bersekretariat. Keleluasaan menjadi gambaran betapa aktivitas keagamaan senantiasa mendapatkan tempat untuk tetap berlangsung. Tidak mendapatkan hambatan apapun juga.

Perguruan tinggi berdiri dilandasi dengan semangat keberagamaan. Walaupun demikian, pendidikan tinggi itu tidak dikelola secara ekslusif. Di Universitas Victory yang didirikan yayasan Protestan, dosen dan mahasiswa juga berasal dari kalangan muslim. Sementara di Universitas Muhammadiyah Sorong dan STKIP Muhammadiyah Sorong, keduanya memberikan keleluasaan untuk membentuk organisasi mahasiswa Protestan dan Katolik. Bahkan sejak berdiri, perguruan tinggi tersebut memberikan tempat khusus untuk kebaktian dan acara Natal yang menggunakan nama universitas secara resmi. Badan Eksekutif Mahasiswa (BEM) Universitas Muhammadiyah Sorong dijabat mahasiswa dengan tidak memperhatikan latar belakang keagamaan. Sehingga dalam beberapa kesempatan ketua umum BEM justru berasal dari Protestan atau Katolik. Politeknik Santa Paul yang dikelola yayasan Katolik, juga mebuka pintu seluas-luasnya bagi mahasiswa muslim. Termasuk pula bagi dosen untuk berkiprah dan menempati posisi akademik sehingga jenjang tertinggi. Di Santa Paul ini, mahasiswa muslim membentuk komisariat Himpunan Mahasiswa Islam dan juga Kesatuan Mahasiswa Muslim Indonesia. Pihak rektorat di 
masing-masing perguruan tinggi menjadikan ini sebagai sebuah keragaman yang akan memperkaya universitas dan sekolah tinggi.

Penerimaan perbedaan menjadi gambaran bahwa sesungguhnya agama hanyalah dijadikan sebagai alat untuk membentuk legalitas formal dan mengusahakan berdirinya lembaga pendidikan. Sementara dalam proses pengembangan tidak lagi secara terbatas menerima mahasiswa dari kalangan internal agama tertentu. Itu berlaku bagi setiap lembaga. Mereka membuka diri untuk secara bersama-sama dengan umat agama lain dalam memberikan fungsi pelayanan pendidikan. Sebelum terdapat peraturan kewajiban menyediakan dosen agama sesuai dengan keyakinan masing-masing mahasiswa, setiap universitas di Papua dan Papua Barat sudah menerapkan pola pendidikan seperti itu. Bukan saja di tingkatan perguruan tinggi, bahkan ini dijalankan sejak di pendidikan dasar. Sekolah-sekolah di Tanjung Kasuari, Saoka, dan Rufei, sekalipun mereka memiliki jarak dari Kota Sorong dan memiliki keterbatasan untuk mendatangkan guru agama, tetap saja mereka menyediakan guru untuk masing-masing agama. Sehingga setiap murid belajar sesuai dengan keyakinannya masing-masing. Tidak satupun murid yang tidak belajar agama hanya karena alasan ketiadaan guru. Seturut dengan peran serta kepala sekolah dan dinas pendidikan dalam memberikan layanan pendidikan yang sama dan setara kepada setiap anak bangsa.

Demikian pula dalam keadaan ketika Madrasah Aliyah Negeri (MAN) dan Madrasah Tsanawiyah Negeri (MTsN) yang ada di Kota Sorong memiliki keterbatasan penyediaan guru, Dinas Pendidikan Kota Sorong menugaskan guru secara khusus mengajar di suatu MAN dan MTsN. Mereka diperbantukan untuk memaksimalkan fungsi pelayanan madrasah. Padahal secara kelembagaan, tanggung jawab manajemen madrasah berada di Kementerian Agama. Menyadari keterbatasan ini, pihak dinas pendidikan tidak menghiraukan pola birokrasi. Justru guru-guru yang mereka miliki ditempatkan di madrasah untuk memberikan fasilitas pendidikan kepada anak-anak bangsa dengan peluang yang sama. Padahal, pejabat di dinas pendidikan sebagian besar berlatarbelakang Protestan. Sekali lagi, ini membuktikan bahwa agama bukanlah penghalang dan penyekat dalam urusan pendidikan. Kepentingan dan persoalan yang lebih besar adalah 
seperti akses pendidikan dan usaha mencerdaskan siswa-siswi. Status agama justru dikesampingkan dan tidak menjadi pertimbangan dalam memberikan pelayanan publik. Saling membantu, kerjasama, dan pengertian menjadi dasar bagi usaha menggerakkan pendidikan.

Kepemimpinan berlangsung secara demokratis. Berdasar pada kemampuan seseorang yang terhitung layak untuk menempati posisi vital dalam pelayanan publik. Sebelum Ramadhan 1436 H/2015 M, Muhammad Rahman, alumni Institut Pemerintahan Dalam Negeri (IPDN) yang berasal dari Sulawesi Selatan, dilantik menjadi Kepala Badan Perencanaan Pembangunan Daerah. Sekalipun Walikota Sorong beragama Protestan, kemampuan Rahman menjadi pertimbangan utama. Pemerintahan berlangsung dengan dilandasi semangat pengelolaan kepentingan rakyat. Sebagaimana juga di Kabupaten Sorong, Bupati Sorong mengangkat Sekretaris Daerah yang beragama Islam. Paduan kepemimpinan di kedua wilayah ini juga menjadi semakin kuat dengan Bupati yang didampingi wakil dari agama Islam. Begitu pula di Kota Sorong, wakil walikota yang dijabat oleh muslim. Kesemuanya menunjukkan ada penerimaan secara luas kepemimpinan seorang muslim dalam politik dan birokrasi. Sehingga walaupun penduduk di beberapa lokasi lebih dominan beragama Protestan dan Katolik, namun tidak membatasi aparatur yang terbaik untuk masuk dan memimpin struktur pemerintahan.

\section{Papua Masa Kini dan Masa Depan}

Musabaqah Tilawatil Quran (MTQ) tingkat Nasional menjadi tanda bahwa Islam di Papua Barat merupakan akumulasi kerja keras dan kerja sama. Saat pelaksanaan MTQ di Batam 2014, Papua Barat menempati posisi empat besar. Hanya dikalahkan oleh Kepulauan Riau, Jawa Barat, dan Jakarta. Ketika pelaksanaan MTQ tingkat Papua Barat usai dilaksanakan di Raja Ampat, persiapan untuk menuju ke MTQ Nasional senantiasa didukung oleh Pemerintah Provinsi Papua Barat. Padahal tidak semua aparatur adalah muslim. Namun demikian, mereka melihatnya sebagai bagian dari kebanggaan daerah. Tidak memandang sebagai acara bagi umat Islam saja. Tetapi kesempatan untuk mengangkat citra dan harkat provinsi secara keseluruhan. 
Kepanitiaan MTQ memiliki latar belakang agama yang berbeda mulai dari tingkat distrik sampai provinsi selama mengawal persiapan menuju MTQ Nasional. Panitia tidak saja berasal dari unsur aparat pemerintah daerah yang muslim, tetapi juga dari pendeta dan pemuda gereja. Mereka menjadi bagian inti dari pelaksanaan MTQ. Kerja keras dilakukan secara bersama karena hanya satu keinginan yaitu memperlihatkan prestasi di tingkat nasional. Kebersamaan menjadi kata kunci bagi upaya tersebut. Sementara persaudaraan menjadi bagian yang menyatukan, walaupun dengan agama yang berbeda.

Kekerasan yang berkobar di Maluku pada akhir 2000 sampai beberapa tahun berikutnya tidak meluas sampai ke Papua. Walaupun secara geografis jarak antara Kota Ambon dan Kota Sorong hanya ditempuh dengan semalam ketika menggunakan kapal laut. Namun kedekatan ini tidaklah memiliki makna apa-apa. Kobaran kekerasan yang menggunakan sentimen agama untuk tetap menghabisi kelompok lain justru tidak dipedulikan di Kota Sorong. Padahal kekhawatiran akan terjadinya kejadian serupa senantiasa menghantui penduduk Kota Sorong. Tetapi sampai berdamainya pendudukan Maluku, tidak satupun perkelahian di Papua Barat terjadi karena dampak dari kejadian di Maluku. Justru ini dijadikan kesempatan untuk saling mengingatkan bahwa kerugian yang terjadi di Maluku jangan sampai terjadi di Papua Barat. Kerugian tidak saja dalam aspek material terlebih lagi dalam urusan emosional dan juga akan menguras lebih banyak energi sekaligus menghancurkan sendi-sendi modal sosial masyarakat.

Tidak saja antar umat beragama. Secara internal umat Islam juga menyatukan diri dalam Yayasan Pendidikan Islam di Tanah Papua (YAPIS), sehingga perbedaan antara organisasi kemasyarakatan juga dapat diredam. Demikian juga dengan YPK dan YPPK, sehinga masing-masing agama berusaha menjaga kekuatan harmoni secara internal dan eksternal. Ketiga organisasi ini tumbuh dan berkembang dengan nama khas dari Tanah Papua, yang di belahan Indonesia lain tidak ditemukan. Masing-masing organisasi secara internal saling berusaha memberikan pengakuan kepada yang lainnya dan duduk bersama dalam majelis. Dalam kondisi seperti ini, pemerintah menjadikan relasi dengan organisasi keagamaan melalui satu pintu, agar terjadi dialog yang saling 
menguntungkan. Dalam hal ini, pemerintah juga secara khusus memberikan kesempatan yang sama kepada setiap penduduk, apapun agamanya. Ketika pembentukan Majelis Rakyat Papua (MRP) umat Islam diwakili oleh Majelis Ulama Indonesia (MUI).

Perluasan Masjid At-Taubah di Malanu, Kota Sorong justru didukung dengan adanya kerelaan pemilik lahan yang beragama Protestan menyerahkan tanahnya. Walaupun dibayar dengan sejumlah uang tetapi harga yang diberikan kepada pengurus masjid jauh di bawah harga pasar. Ini sekaligus sebagai dukungan bagi masjid untuk mendapatkan lahan di tengah wilayah Malanu yang merupakan kawasan padat dengan pemukiman dan salah satu pusat bisnis di Kota Sorong. Sementara itu, tanah yang dimiliki Sekolah Tinggi Agama Islam Negeri (STAIN) Sorong justru diserahkan kepada gereja untuk dijadikan sebagai lahan dalam membangun rumah ibadah. Dua hal ini membuktikan, sekalipun tempat ibadah seringkali menjadi bagian esensial dan emosional dalam kehidupan beragama, justru tidak menghalangi penganut agama berbeda saling berbagi ruang mendukung berdirinya gereja ataupun masjid.

Selama proses penghimpunan dana untuk membangun masjid, menjadi kesempatan seluruh warga kota untuk saling bahu membahu. Bazar salah satunya wadah untuk bertemu. Saat panitia masjid mengedarkan kupon yang menjadi tanda sumbangan, maka seluruh warga secara bergotong royong membeli sesuai dengan kemampuan masing-masing. Saat bazar dilaksanakan, masyarakatpun datang dan bertemu untuk saling menyapa. Kupon bazar yang dibeli dapat digunakan untuk ditukarkan untuk mendapatkan makanan yang tersedia. Adapun penanganan itu disiapkan oleh jamaah masjid sekitar tanpa memandang latar belakang agama.

Paparan ini menunjukkan bahwa sesungguhnya Papua dan Papua Barat adalah bagian dari harmoni keberagamaan yang terbentuk berdasarkan situasi sosial. Pilar harmoni itu justru dibangun dari institusi keluarga dan akhirnya menyebar dalam lingkungan masyarakat secara luas. Hal ini akhirnya menjadi praktik yang jamak dan dijadikan sebagai keharusan. Agama tidaklah menghalangi pembentukan kerukunan, justru dengan agama itulah menjadi ajang membangun kesepahaman dan akhirnya saling mendukung antara satu kelompok dengan kelompok yang lain. 
Bahkan ini sudah dimulai dari bagian terkecil yaitu individu dalam keluarga. Mereka tidak mempermasalahkan pilihan anggota keluarga lain jikalau memilih agama yang berbeda dari keluarga besar. Dalam sebuah keluarga menjadi sebuah kelaziman adanya perbedaan. Justru dengan perbedaan itu, mereka berusaha saling memberikan dukungan merayakan tradisi keagamaan.

Artikel ini juga menunjukkan bahwa agama sesungguhnya bukanlah bagian konflik ${ }^{13}$. Hanya saja para pengikutnya kemudian menjadikan agama sebagai komoditas utama ketika berusaha untuk mempertahankan kebencian. Padahal sejatinya, agama tidaklah menjadi pemicu konflik ${ }^{14}$. Justru agama dapat menjadi alat untuk saling mendamaikan dan membangun relasi sosial dalam masyarakat ${ }^{15}$. Bahkan dalam kepemimpinan yang senantiasa menjadikan agama sebagai semangat, terbangun keinginan untuk saling mendukung di antara anggota masyarakat ${ }^{16}$. Agama juga terkadang dijadikan sebagai komoditas untuk meraih kepentingan sesaat $^{17}$ (Farrell, 2014). Padahal, sejatinya agama melampaui semua itu. Dalam beberapa hal, justru agama akan lebih produktif jika digunakan untuk menjadi bagian yang mempersatukan ${ }^{18}$ (Gebert,

13 F. B Aliyev, "Problems of Interaction Between State and Economy Under the Post-Communist Transition" dalam Humanomics, Volume 23, No. 2, (2007), h. 73-82.

14 L. Allen, K. Quinlivan, C. Aspin, F. Sanjakdar, A. Brömdal, dan M. Lou Rasmussen, "Meeting at the crossroads: re-conceptualising difference in research teams" dalam Qualitative Research Journal, Volume 14, No. 2, (2014), h. 119-133.

15 M. McCormack, L. Brinkley-Rubinstein, dan K. L. Craven, "Leadership Religiosity: a Critical Analysis" dalam Leadership \& Organization Development Journal, Volume 35, No. 7, (2014), h. 622-636.

16 C. La Ferle dan K. Chan, "Determinants for Materialism Among Adolescents in Singapore" dalam Young Consumers, Volume 9, Nomor 3, (2008), h. 201-214.

17 F. Farrell, "A critical investigation of the relationship between masculinity, social justice, religious education and the neo-liberal discourse", dalam Education and Training, Volume 56, Nomor 7, (2014), h. 650-662.

18 D. Gebert, S. Boerner, \& D. Chatterjee, "Do religious differences matter? An analysis in India", dalam Team Performance Management, Volume 17, Nomor 3/4, 2011, h. 224-240. 
Boerner, \& Chatterjee, 2011). Nilai agama akan menjadi penopang bagi keberadaan kehidupan kemanusiaan ${ }^{19}$ (Dean, 2014).

Akhirnya, artikel ini menjadi bagian yang menunjukkan betapa agama menjadi perekat bagi kehidupan. Dalam pengalaman Perancis, agama tidak lagi dipersoalan ketika memasuki ruang budaya $^{20}$ (Cintas, Gosse, \& Vatteville, 2013). Hanya saja, diperlukan sebuah jembatan yang dapat mendialogkan bagaimana agama menjadi bagian yang menyatu dalam kebudayaan ${ }^{21}$ (Irwin \& Bradshaw, 2011). Tantangan ini dapat dilalui jika pihak-pihak yang berbeda bisa saling menerima keberadaan kelompok yang lain. Dalam kaitan dengan Papua dan Papua Barat, persamaan etnisitas menjadi aspek pemersatu dibandingkan dengan keberagamaan, sehingga dengan mudah terbangun saling pemahaman. Sementara itu, masyarakat yang terbagi atas identitas yang berbeda, dapat saja menyatu jikalau aspek yang berbeda itu bukan menjadi persoalan ${ }^{22}$ (Kachuyevski \& Olesker, 2014). Artikel ini menegaskan bahwa dengan kesatuan masyarakat, akan menjadi bagian yang sangat perlu dalam membentuk kesamaan pandangan sehingga melahirkan produktif untuk kepentingan bersama.

\section{E. Penutup}

Artikel ini menegaskan bahwa agama bukanlah sebagai pemicu sebuah konflik. Justru agama dijadikan sebagai kambing hitam sumber konflik. Padahal tidaklah pernah ada perkelahian karena perbedaan dimulai dari sisi agama. Hanya saja, ada sisi lain yang memulai dan kemudian agama diikutkan sebagai bagian dari konflik. Papua menunjukkan bahwa agama justru menjadi perekat

19 J. Dean, "Muslim values and market value: a sociological perspective", dalam Journal of Islamic Marketing, Volume 5, (November 2012), h. 20-32.

20 C. Cintas, B. Gosse, \& E. Vatteville, "Religious identity: a new dimension of HRM? A French view", dalam Employee Relations, Volume 35, Nomor 6, (2013), h. 576-592.

21 J. Irwin, \& K. Bradshaw, " The ethics challenge: establishing an ethics ambassador network to help embed an ethical culture", dalam Strategic HR Review, Volume 10, Nomor 4, (2011), h. 26-32.

22 A. Kachuyevski, \& R. Olesker, "Divided societies and identity boundaries: a conflict analysis framework", dalam International Journal of Conflict Management, Volume 25, Nomor 3, (2014), h. 304-321. 
keguyuban masyarakat. Dari soal pendidikan sampai pada perayaan ritual keagamaan dijalankan dengan semangat persaudaraan. Kesatuan dan persatuan dalam masyarakat senantiasa diupayakan agar saling mengerti dan membantu. Identitas agama semata-mata merupakan soal pilihan pribadi yang dipertanggungjawabkan kepada Sang Pencipta dan tidak mengurangi hubungan baik antar sesama manusia.

Relasi keagamaan tercipta atas dasar harmoni dan saling pengertian. Lembaga-lembaga pendidikan dan institusi sosial lain tetap berjalan dan berkembang dengan adanya sikap saling memberi kesempatan dan peluang yang sama tanpa memandang status agama. Justru agama memperkuat lembaga secara positif. Kemudian dengan spirit itu hubungan kemanusiaan terbangun untuk kepentingan saling mencerdaskan dan memanusiakan. Maka, bukanlah halangan bagi seorang mahasiswa muslim untuk kuliah di perguruan tinggi yang dikelola oleh Yayasan Katolik ataupun Yayasan Protestan. Demikian pula sebaliknya, seorang mahasiswa Protestan dan Katolik justru menyelesaikan sarjana di perguruan tinggi yang dijalankan Muhammadiyah. Sebelumnya, justru mereka menamatkan pendidikan menengah yang dikelola Al-Maarif, lembaga pendidikan di bawah naungan Nahdhatul Ulama. Hubungan seperti ini justru saling memperkuat dengan tetap mempertahankan kesetiaan kepada masing-masing agama mereka sendiri. Sementara itu pihak sekolah dan perguruan tinggi juga mengusahakan guru dan dosen yang seiman dalam mengajarkan agama. Ini berlangsung ketika praktik seperti ini belum diatur oleh Undang-Undang Sistem Pendidikan Nasional.

Perayaan Natal dan Idul Fithri menjadi bagian dari pertemuan keluarga besar. Perayaan hari besar keagamaan seperti ini merupakan kesempatan berkumpul. Di saat itu pulalah mereka berbagi dan saling mengirimkan makanan atau bingkisan antar sesama. Kondisi-kondisi seperti ini menjadi bagian tradisi yang sudah berlangsung turun temurun, sehingga perbedaan agama tidaklah menjadi persoalan bagi setiap orang. Secara bebas, individu memeluk agamanya kemudian keterhubungannya dengan penduduk kota yang lain karena mereka adalah bagian wilayah yang harus turut bertanggungjawab memelihara kedamaian yang sudah diwariskan oleh pendahulu. Klaim kebenaran cukuplah dilakukan 
secara khusus di dalam rumah ibadah. Tetapi ketika berjumpa dengan orang lain, maka tidaklah perlu menjadikan agama sebagai bagian yang harus dijadikan sebagai pembeda justru itu dipergunakan untuk saling menghormati pilihan yang berbeda. Dalam beberapa kesempatan, pendirian masjid dan gereja justru didukung oleh masyarakat lingkungan sekitar yang berbeda agama. Sehinga tidak kesulitan membangun rumah ibadah, sekalipun itu di sekelilingnya terdapat masyarakat yang menganut agama berbeda. Bahkan dalam urusan tanah justru dihibahkan oleh pihak yang berbeda agama pula. []

\section{DAFTAR PUSTAKA}

Durkheim, E., "The Elementary Forms of Religious Life" dalam M. Lambek (ed.), A Reader in the Anthropology of Religion, Malden: Blackwell Publishing, 2002.

Ramble, C., The Navel of the Demoness: Tibetan Buddhism and Civil Religion in Highlight Nepal, Oxford: Oxford University Press, 2008.

Stevens, S., "Annapurna Conservation Area: Empowerment, Conservation and Development in Nepal" dalam Stevens, S. (ed.), Conservation Through Cultural Survival, Washington D.C.: Island Press, 1997.

West, P., Conservation is Our Government Now: The Politics of Ecology in Papua New Guinea, Durham: Duke University Press, 2006.

\section{Jurnal:}

Aliyev, F. B, "Problems of Interaction Between State and Economy Under the Post-Communist Transition" dalam Humanomics, Volume 23, No. 2, 2007.

Allen, L., K. Quinlivan, C. Aspin, F. Sanjakdar, A. Brömdal, dan M. Lou Rasmussen, "Meeting at the crossroads: reconceptualising difference in research teams" dalam Qualitative Research Journal, Volume 14, No. 2, 2014.

Cintas, C., Gosse, B., \& Vatteville, E. Religious identity: a new dimension of HRM? A French view. Employee Relations, Volume 35, Nomor 6, (2013) 
Dean, J. Muslim values and market value: a sociological perspective. Journal of Islamic Marketing, Volume 5, November 2012.

Farrell, F. A critical investigation of the relationship between masculinity, social justice, religious education and the neoliberal discourse. Education and Training, Volume 56, Nomor 7, 2014.

Gebert, D., Boerner, S., \& Chatterjee, D. Do religious differences matter? An analysis in India. Team Performance Management, Volume 17, Nomor 3\&4, 2011.

Irwin, J., \& Bradshaw, K. The ethics challenge: establishing an ethics ambassador network to help embed an ethical culture. Strategic HR Review, 10 Nomor 4, 2011.

Kachuyevski, A., \& Olesker, R. Divided Societies and Identity Boundaries: a Conflict Analysis Framework. International Journal of Conflict Management, Volume 25, Nomor 3, 2014.

La Ferle, C. dan K. Chan, "Determinants for Materialism Among Adolescents in Singapore" dalam Young Consumers, Volume 9, Nomor 3, 2008.

McCormack, M., L. Brinkley-Rubinstein, dan K. L. Craven, "Leadership Religiosity: a Critical Analysis" dalam Leadership \& Organization Development Journal, Volume 35, No. 7, 2014.

Wekke, I. S. dan Lubis, M. A. "A Multicultural Approach in Arabic Language Teaching: Creating Equality at Indonesian Pesantren Classroom Life" dalam Sosiobumanika, Jurnal Pendidikan Sains Sosial dan Kemanusiaan, Volume 1, Nomor 2, 2008.

Wekke, I. S. dan Y. R. Sari, "Tifa Syawat dan Entitas Dakwah dalam Budaya Islam: Studi Suku Kokoda Sorong Papua Barat" dalam Thaqafiyyat, Jurnal Kajian Budaya Islam, Volume 13, Nomor 1, 2012.

Wekke, I. S., "Islam dan Adat dalam Pernikahan Masyarakat Bugis di Papua Barat" dalam Thaqafiyyat, Jurnal Kajian Budaya Islam, Volume 13, Nomor 2, 2012.

, "Masjid di Papua Barat: Tinjauan Ekspresi Keberagamaan Minoritas Muslim dalam Arsitektur" dalam El Harakah, Jurnal Budaya Islam, Volume 15, Nomor 2, 2013. 
, "Pendidikan Islam dan Pemberdayaan Masyarakat: Tinjauan Pendidikan Vokasional Pesantren Roudhatul Khuffadz, Sorong" dalam Hermenia, Jurnal Kajian Islam Interdisipliner, Volume 10, Nomor 1, 2011.

, "Pesantren dan Pengembangan Kurikulum Kewirausahaan: Kajian Pesantren Roudhatul Khuffadz Sorong Papua Barat" dalam Jurnal Inferensi, Volume 6, Nomor 2, 2012.

"Religious Education and Empowerment: Study on Pesantren in Muslim Minority West Papua" dalam Miqot, Jurnal Ilmu-ilmu Keislaman, Volume 37, Nomor 2, 2013.

\section{Makalah dan Media Massa:}

Wekke, I. S., E. Gunaisah, Suyatno, "Identitas dan Ekspresi Keberagamaan Nelayan Muslim: Masyarakat Pesisir Raja Ampat Papua Barat", Prosiding dalam Seminar Nasional Kelautan dan Perikanan, Politeknik Kelautan dan Perikanan Sorong, 10 Maret 2015. 